\title{
DESCRIÇÃO DA LIBERDADE NUMA PERSPECTIVA DETERMINISTA: ARISTÓTELES NO CONTEXTO DA CIÊNCIA MODERNA*
}

\author{
Régis Antônio Coimbra**
}

SÍNTESE - O autor esboça seu projeto de apresentar a liberdade como independente da versão forte - ontológica - da contingência; e discutir certas afinidades indeterministas de Aristóteles com a interpretação dominante da física quântica, em contraste com o determinismo da ciência moderna.

PALAVRAS-CHAVE - Liberdade, determinismo, Aristóteles.

\begin{abstract}
The author sketches his project of presenting the freedom as independent of the strong version - ontological - of the contingency; and to discuss certain indeterministic likeness of Aristotle with the quantum physics dominant interpretation, in contrast with the determinism of the modern science.

KEY WORDS - Freedom, determinism, Aristotle.
\end{abstract}

\section{Contextualização desta commicação neste congresso sobre dialética ${ }^{1}$}

Reinterpretada no sentido de buscar um diálogo com a tradição dialética hegeliano-marxista que conheço e compreendo muito pouco ou nada, minha comunicação em importante medida visa mostrar como o aparente conflito entre a caracterização do ser como ou (1) determinado, ou (2) mais ou menos indeterminado não comporta qualquer sintese dialética, pois não é um verdadeiro conflito de

* Este título é incorrigivelmente inadequado e o mantenho apenas como a um nome próprio, pois foi assim que este texto foi parcialmente apresentado em uma comunicação de 30 minutos no dia 4 de maio de 1998, no Congresso Internacional Dialética em Porto Alegre, promovido pelo curso de Pós-Graduação em Filosofia da Pontificia Universidade Católica do Rio Grande do Sul. Um título mais representativo, ainda que pior por outros aspectos, seria algo do tipo: "comentários sobre liberdade e determinismo, sugerindo algumas afinidades entre Aristóteies e a interpretação dominante da física quântica, e dos megáricos com a ciência moderna".

** Mestrando do Curso de Pós-Građuação em Filosofia da Universidade Federal do Rio Grande do Sul - UFRGS.

1 Dada minha ignorância praticamente totai das tradições dialéticas, especiaimente da hegeliana, fiz uma rápida consulta aos livros "Sobre a Contradição" e "Dialética para Principiantes" do professor Carlos Cirne-Lima. Se entendi bem, tal dialética é um método de confrontar representações conflitantes parcialmente válidas e obter novas representações que, coordenando o que havia de válido e corrigindo ou exciuindo ("superando") o que havia de equivoco ou absurdo nas conflitantes iniciais, leve a um melhor ou maior conhecimento. 
opiniões divergentes ("contraditórias" no sentido de parte da tradição dialética), mas um par de teses contraditórias (no sentido lógico usual) igualmente razoáveis, no qual não é possivel declarar uma verdadeira e outra falsa senão por um juízo de conveniência ou simpatia não teóricas.

As opiniões conflitantes originais possiveis seriam, na base grega, (1) se o ser é absolutamente indeterminado, absolutamente plural e caótico - numa interpretação rađical e provavelmente caricatural do "tudo flui" de Heráclito - e (2), opostamente (e não ainda contraditoriamente), se o ser é totaimente determinado e em si estático - como na imagem da esfera perfeita de Parmênides.

De modo pragmático-transcendental ${ }^{2}$ se elimina a hipótese de que o ser seja totalmente indeterminado. $\mathrm{O}$ que sobra é que $\mathrm{o}$ ser é necessariamente (conforme 0 argumento pragmático-transcendental) ao menos em parte determinado. Quanto a se "o ser é absolutamente determinado", fica como uma extrapolação não absurda mas desnecessária.

Se alguns eventos não tem causa, eles são simplesmente, como de resto também se concebe ser Deus, ou o Universo natural não criado. No entanto, como a razão só pode refletir sobre o que é determinado, é natural para o homem pensar que o ser é totalmente determinado. Pois o ser que podemos racionalmente conceber ou tratar é o determinado, no que ele é determinado. Pensar o ser enquanto não determinado seria como perguntar sobre as causas inexistentes de um evento arbitrário; ora, ou simplesmente não há tais causas ou elas não são causas inexistentes, mas causas pura e simplesmente. Pela mesma razão, não é adequado dizer, numa matriz contingencialista ${ }^{3}$ coerente, que um evento futuro indeterminado será determinado pelo mundo, pois nada determinará um evento indeterminado, no que ele tem de indeterminado - ele simplesmente acontecerá ou não, não decidido pelo mundo ou ser, mas decidindo o mundo, ou o ser.

Então, conforme o argumento pragmático-transcendental, é necessário que o ser seja ao menos em parte determinado. Como para nós só é pensável de modo racional o que é determinado, tendemos a pensar que o ser é absolutamente determinado. Mas alguns - qual aparentemente Aristóteles - consideraram absurdo que o ser seja absolutamente determinado e assim impossivel a contingência forte (metafísica), pois pensaram que, se a contingência forte é impossivel, também a liberdade é impossivel, o que é pelo, argumento pragmático-transcendental, absurdo (impossivel de pensar com sentido).

Considerar a liberdade como dependendo da contingência forte me parece um equívoco, pois a liberdade, como a consigo compreender, em nada depende da indeterminação do ser, ou da contingência forte, no sentido ontológico. A liberda-

2 Por pragmático-transcendental entendo, de Aristóteles aos contemporâneos, a argumentação por redução ao absurdo que compromete o agente com seu ato, sob pena de contradição. Por exemplo, é necessário supor que o homem seja racional, pois argumentar o contrário seria contraditório, pressupondo a legitimidade da própria argumentação; tampouco o ser pode ser totalmente indeterminado, ou não seria possivel nenhum discurso ou sujeito, hipótese impossivel de ser mantica por qualquer sujeito discursante.

3 Vou usar o termo contingencialista - possivelmente um neologismo - para me referir a posição ontológica indeterminista, que supõe que o ser é essencialmente, em maior ou menor medida, indeterminado a ser de um ou de outro modo, oposta a determinista. 
de, enquanto (com o perdão da redundância) conceito racional, depende da determinação do ser, embora seja indiferente se o ser é totalmente ou apenas em parte determinado. Ressalto, entretanto, que a liberdade só é possivel de ser pensada no que o ser é determinado.

Se o ser é em parte indeterminado, no que ele é indeterminado não é possivel qualquer discurso racional. A possivel medida de indeterminação do ser em si é impossivel de ser pensada senão como desconhecida e impossivel de conhecer como tal. Para nós o ser é necessariamente determinado, ainda que em si não seja totalmente determinado.

O ser para nós só pode ser pensado como absolutamente determinado; em si, "talvez" (mas nunca saberemos) tenha partes indeterminadas ocorrendo no sentido forte de contingência, ou seja, coisas novas ocorrendo simplesmente, sem causa. Como não é possível distinguir os eventos (1) sem causa dos eventos (2) de causa meramente desconhecida ou impossivel de conhecer, a hipótese de eventos (1) sem causa é inútil, enquanto que a dos eventos (2) de causa desconhecida é produtiva - e alentadora, no sentido de dar sentido às nossas investigações.

Embora eventos de causas desconhecidas e eventos sem causa sejam indistinguíveis para nós, todavia a hipótese de uma causa desconhecida é não só metafisicamente concebível como também epistemologicamente justificada - isto é, pela possibilidade de, insistindo, se encontrar uma causa mais ou menos atribuível ao evento. Ao contrário, a hipótese de uma causa impossivel de conhecer distinta da simples inexistência de causa - e vice-versa - é só metafisicamente concebivel, precisamente como o que está para além da potência da ciênicia humana (isto, é, de sujeitos racionais finitos como nós).

De modo mais esquemático, recomendo que minha argumentação seja acompanhada tendo-se em vista os seguintes cinco postos:

1) Se há o Ser absoluto, não pode haver contingência no sentido forte; e, viceversa, se há contingência no sentido forte, não pode haver o Absoluto. Ou a contingência deve ser interpretada como efeito de nossa perspectiva finita - nossa ignorância constitutiva -, ou o Absoluto é uma extrapolação da razão, ou seja, o ser não está dado, seja para nós, seja em si ou para si.

2) Não é possivel saber se há o Ser absoluto, com tudo ontologicamente determinado, ou, ao contrário, se há uma contingência no sentido forte, com mais ser surgindo do nada. Portanto a contingência deve ser interpretada como efeito de nossa perspectiva finita - nossa ignorância constitutiva - e o Absoluto é suposto 'apenas por extrapolação.

3) A liberdade é igualmente compativel tanto com o determinismo ontológico da hipótese de haver o ser absoluto quanto com a hipótese de haver contingência no sentido ontológico (e não apenas epistemológico), pois o conceito de liberdade só faz sentido relativamente à vontade ser parte da causa de certos eventos - e assim independente de a própria vontade ser causada (no sentido de ontologicamente determinada) ou aleatória (no sentido de, em maior ou menor medida, ser sem causa, surgindo do nada). Uma vontade totalmente indeterminada.(gratuita) seria impossivel de identificar com o agente, pois o que não é determinado não é derivado de nada, e a vontade assim não seria do agente, mas determinaria o agente. 
A única hipótese em que a liberdade seria impossivel - contrafactual relativamente à nossa consciência e nossa pragmático-transcendental suposição de que somos racionais - é a do ser não ser em nada determinado, absolutamente arbitráno e aleatório, uma pluralidade absoluta e não um ser absoluto, nada se seguindo de nada. Neste caso, também a vontade não teria nenhuma relação com qualquer outro evento; nem poderia ser dita propriamente vontade - como, de resto, nada poderia ser dito.

4) Seja o ser absoluto (e assim determinado e ao menos em si já dado), seja o ser ao menos em parte ontologicamente indeterminado, a liberdade só faz sentido no que o ser é determinado, pois depende da conexão da vontade com a ação. A ação ética por sua vez só faz sentido no que a própria vontade é determinada pela pressão do ambiente sobre a sensibilidade do agente que reage com segundo sua espontaneidade intrínseca; no caso humano tal espontaneidade é em parte racional. A vontade sem causa e eventual conseqüente ação, se existe, é apenas acidental ou aleatória, e não ética, ou racional.

5) A prova da liberdade, ou mais precisamente sua defesa ou fundamentação, é de natureza pragmático-transcendental: não é possível pensar que não somos livres, pois pensar é uma ação, e só age propriamente quem é livre; logo, quem pensa que pensa tem que se supor livre.

\section{Â contingência - de Aristóteles à física contemporânea - e sua indiferença para a liberdade $e^{4}$}

Alguns interpretam que, no capítulo 9 do Tratado da Interpretação, Aristóteles rejeita o fatalismo lógico do megárico Diodoro Crono como evidentemente inaceitável porque se tudo ocorre por necessidade, a deliberação é vã e a ação é impossivel. Insistindo na prioridade do ser sobre a verdade - ou seja, porque o ser é de determinado modo é que uma proposição é verdadeira (ou é falsa), e não ao contrário - Aristóteles parece se comprometer com certa noção forte de contingência, na qual hoje não está totalmente determinado o que será o caso amanhã, notadamente em proposições do tipo "eu vou ao cinema amanhã", ou "uma batalha naval ocorrerá amanhã" - proposições singulares (quanto a quantidade), contingentes (quanto a matéria) e sobre o futuro (quanto ao tempo).

4 Traço esquematicamente o percurso da (1) noção de contingência ontológica que Aristóteles, contra os eleatas (Parmênides, Zenão e Diodoro Crono), concebe na metafisica e aplica na física (para os eventos sublunares), e na ética (para a açâo humana), com (2.1) a interpretação cristã da contingência como ilusão inerente à perspectiva finita humana, entendendo medievais que o ser é totalmente determinado, dado que totalmente conhecido por Deus, mesmo que - respeitando a posição de Aristóteles - o tempo seja real, e Deus - o da caracterização cristã - ainda não tenha criado o mundo inteiro (ainda não, por exemplo, o futuro), pois Deus se conhece perfeitamente, e sabe o que fará; de modo semelhante, (2.2) a concepção da ciência moderna do ser é determinista tanto para os eventos supralunares como para os sublunares - e com Freud, tardia e explicitamente, não apenas os eventos físico-quimicos neurológicos mas inclusive os cognitivo-pulsionais psiquicos são concebidos numa matriz determinista; só (3) com a ciência contemporânea - notadamente na fisica - voltou-se a levantar com força (ainda que de modo polêmico) a hipótese de o ser em parte ser indeterminado. No meu entender (4), as posições determinista e contingencialista são indecidiveis e indiferentes para a descrição da liberdade, que é incompatível apenas com o acaso absoluto. 
Meu ponto é quanto a refutação do fatalismo lógico (ou seja, o que das regras lógicas pretende derivar a necessidade para todos os eventos, sem contingência) e sua importância para o conceito de liberdade. Minha posição é de que a questão é epistemológica: a contingência é uma caracterização epistemológica, derivada do fenômeno da incerteza, decorrente de nossa finitude epistemológica. Insistir na indeterminação do ser nos casos em que não podemos ter certeza é um erro metafísico por exagero.

Aliás, Aristóteles, no célebre capitulo nove do Tratado da Interpretação, onde aparece a argumentação com a proposição "haverá amanhã uma batalha naval", refuta efetivamente apenas que considerações lógicas - em particular o argumento "dominador" de Diodoro Crono - garantam um determinismo ontológico geral, o que também seria um erro metafísico. O que Aristóteles de fato mostrou foi que os princípios de não contradição e terceiro excluído devem ser tomados como incondicional e atemporalmente válidos para, digamos, o discurso com sentido, enquanto que a bivalência tem validade temporalmente restrita, não se aplicando aos ditos futuros contingentes na acepção própria (mas apenas como bipolaridade, na acepção contemporânea: ter dois e apenas dois valores de verdade possiveis - no caso de Aristóteles, possiveis por uma potência). Com este resultado Aristóteles escapa à interpretação de Diodoro Crono de que, dados os princípios lógicos descritos pelo próprio Aristóteles, a bivalência seria também um princípio incondicionalmente necessário (ou seja, qualquer proposição teria, independentemente do tempo, um valor de verdade determinado - isto é, seria ou de fato verdadeira ou de fato falsa - embora acidentalmente ignorado), e portanto o ser seria completamente determinado de modo atemporal - sendo portanto o tempo enquanto passado, presente e futuro uma ilusão decorrente da imperfeita ou ilusória maneira humana de conhecer.

Para Aristóteles, ao lado de eventos absolutamente inexoráveis, como os movimentos estudados pela astronomia, havia eventos constitutivamente indeterminados, ou movidos por uma potência e não por causas suficientes desde sempre dadas ou determinadas. Se prestarmos atenção para o que chamamos hoje de ciência, notaremos que muito do que parecia mais ou menos casual para Aristóteles para nós é rigorosamente inexorável - objetos de ciências mais ou menos exatas não por serem de matérias mais ou menos determinadas, mas por serem mais ou menos fáceis de conhecer à exaustão ou com certo grau de segurança.

Na Metafísica, em theta (livro 9) cap. 3, 1046b29 Aristóteles diz que

“os megáricos afirmam que só se tem potência enquanto se atua, e que quando não se atua não se tem potência; por exemplo, o que não constrói nāo pode construir, e só o pode quem constrói, e assim por diante. Os absurdos em que os megáricos incorrem são fáceis de ver. Pois, evidentemente assim um construtor deixará de o ser quando não constrói, e o mesmo nas demais artes."

Aristóteles argumenta ser evidentemente absurda a posição dos megáricos, mas se ela é absurda, talvez não seja da maneira que a primeira vista parece ser absurda.

Aristóteles pergunta, por exemplo, para onde foi a habilidade de construir quando alguém pára de construir, e pergunta de onde veio quando aquele que 
havia parado de construir volta a fazê-lo de repente. Ora, os megáricos ao dizerem que só pode o que de fato faz - ou que só pode o que de fato ocorre - não se referem a potência no sentido de ser hábil, ter habilidade, etc. Neste sentido, de fato, um homem pode estudar para construir pontes e tornar-se capaz de 0 fazer, embora possa morrer antes de construir uma ponte sequer. Mas para os megáricos ele não tinha real possibilidade (possibilidade real ontologicamente completa, como caracteriza Nicolai Hartman ${ }^{5}$ ) de fazer uma ponte, e apenas nossa ignorância quanto ao fato de que ele morreria em determinada ocasião é que nos faz dizer que ele era capaz de fazer pontes.

0 que ressaltavam os megáricos era que alguém pode ter uma habilidade, como a de construir pontes, mas só a habilidade não é suficiente para que tal pessoa hábil pudesse de fato construir uma ponte. Seriam também necessários os materiais, mão-de-obra, tempo de vida, saúde, autorização, etc. Sem todos os fatores necessários seria impossível se construir a ponte; e se todos esses fatores ocorressem juntos, então necessariamente se construiria a ponte. Para os megáricos, só o absoluto é real; e só há propriamente o necessário. O possivel seria uma modalidade epistemológica e não ontológica, pois relativa à ignorância humana e não a qualquer propriedade intrínseca do ser.

O relativo absurdo megárico seria o da descontextualização - forçada por Aristóteles - do ponto de vista absoluto pressuposto pelos megáricos, no qual tudo é por necessidade ou simplesmente não é. Mas isso não me parece absurdo, e muito menos evidentemente absurdo - principalmente se considerarmos seja o papel do "estava escrito" na influente tradição cristã, seja o determinismo forte da física moderna clássica, notadamente na mecânica newtoniana.

O sentido megárico de possível não é o de possivel "não por uma potência", que Aristóteles exemplifica ${ }^{6}$ como a possibilidade de um homem estar sentado, simplesmente porque não é necessariamente falso que esteja sentado. Muito menos é o de possivel "por uma potência" no sentido de por um princípio de movimento ou mudança ${ }^{7}$ todavia não absolutamente determinado, pois pode mover ou mudar, ou não, dependendo ainda de outros fatores. O sẹntido megárico de possível seria, tentando usar a terminologia de Aristóteles, o de necessário dadas suficientes condições determinadamente capazes ou incapazes de realizar certa mudança ou movimento, isto é, necessário por uma resultante determinada de causas também determinadas.

Dadas todas as condições ou causas envolvidas e suas respectivas magnitudes e determinações, não fará mais sentido dizer que pode suceder de um modo mas também de outro. Para os megáricos só dizemos que pode ou não porque acidentalmente não sabemos se de fato ocorrerá ou não. Neste sentido, de ignorância, é que um pano pode ou não se rasgar, ou amanhã uma batalha naval ocorrer ou não. De fato, apostaram os megáricos e a ciência moderna, há mais ou menos complexas causas em jogo, mas causas determinadas, de resultados inexoráveis.

5 No $22^{2}$ capitulo do segundo volume, Posibilidad y efectividad, de sua Ontologia - Fondo de Cultura Económica, México - primeira edição em alemão, Möglichkeit und Wircklichkeit, de 1937.

6 Na Metafísica, em delta 12, 1019b30.

7 Na Metafísica, delta 12, 1019a35. 
Aplicando este modelo ao exemplo do pano ${ }^{8}$, considerando-se todas as forças que de fato agem ou agirão sobre um manto e as forças do próprio manto, ele necessariamente de fato se rasgará sendo tais e tais, ou se gastará, se forem de fato tais outras. Do mesmo modo, uma batalha naval ocorrerá ou não conforme suas determinações. E assim tudo o mais deste tipo.

Em theta (9) 1047a10 Aristóteles começa a dizer que os megáricos não podem falar do movimento, pois o que está de um jeito não pode estar senão daquele jeito, e o que está de outro, deste outro, mas a posição megárica talvez seja melhor descrita se dissermos que o que agora está de certo modo necessariamente está deste modo agora, e não poderia de fato estar de outro modo. Ou, de maneira ainda mais ilustrativa do que está em jogo, dizer que amanhã tal coisa estará de determinado modo não envolve apenas uma possibilidade, mas também um fato, conhecido ou não, e que apenas nossa ignorância faz parecer meramente possível, ou não necessariamente impossível, que seja de um jeito ou diferente. Na verdade este tipo de determinação forte era aceito sem restrições por Aristóteles para os eventos supra lunares.

Do ponto de vista megárico, todas as mudanças ou movimentos são de fato inexoráveis, sucedendo necessariamente do modo como sucedem e não de outro. Por isso só o homem que de fato construirá pontes pode o fazer, pois a resultante de todos os fatores pertinentes determina que ele o fará; e aquele que de fato não construirá não pode pois a resultante de todos os fatores pertinentes determina que ele não construirá. Isso não é absurdo, embora use o termo "poder" num sentido atemporal, onde não cabe a diferença entre possível e necessário, de resto perfeitamente cabível e mesmo recomendável no contexto epistemologicamente limitado em que dizemos, por exemplo, que "pode ser que não chova na semana que vem". Mesmo a contemporânea teoria do cáos - que alguns preferem chamar de teoria da complexidade - não supõe o acaso, mas pretende dar bons modelos para fenômenos muito complexos - e, assim, justamente poder prever o melhor possivel se choverá ou não na semana que vem ou se simplesmente não será possivel predizer isso aquém de certa margem de erro, senão a partir de tais ou tais definições ainda não observadas, ou só a partir de quinta-feira, por exemplo.

Talvez os megáricos não tivessem pensado exatamente assim, ou não de modo sistemático, e de qualquer modo não estou em condições de determinar isso; tampouco eram tão evidentemente absurdos quanto Aristóteles os pareceu tomar. Mas certamente os modernos pensaram neste sentido causal/determinista forte. Newton ao enunciar a lei da inércia tornou os movimentos sublunares tão necessários quanto os supra lunares, embora eventualmente reconhecesse ser difícil ou impraticável calcular todas as forças agindo durante o rolar morro a baixo de uma pedra, e mais fácil - embora também arriscado - a órbita de um cometa.

Com Freud, mesmo os eventos psíquicos são pensados como causalmente determinados, inclusive reiterando Freud que futuramente talvez se pudesse abandonar a psicanálise como terapêutica conquanto se dominassem os neurológicos determinantes físico-químicos do que ele então chamava de neuroses. Curiosamente, mais ou menos quando Freud traz uma concepção que sujeitava a

Que Aristóteles exemplifica no Tratado da Interpretação 9. 
mente e a ação humana a um determinismo forte, paralelamente alguns setores da física questionaram a necessidade ou conveniência de tal tipo de concepção cau$\mathrm{sal} /$ determinista.

A ciência moderna clássica, diferente da aristotélica, exigiu da correspondente filosofia (moderna) uma distinção mais marcada entre o epistemológico e o ontológico, e uma forte inclinação para apostar mais na determinação do que na indeterminação do ser. Com dados suficientes, então, poder-se-ia predizer com segurança qualquer evento futuro, como culminantemente disse Laplace.

A ciência contemporânea, entretanto, conheceu de modo mais extremo e preciso os limites de nossa possibilidade de conhecer, a ponto de algumas interpretações da teoria quântica, especialmente a interpretação da Escola de Copenhague - com Heisenberg e o princípio da incerteza, e Bohr e o princípio da complementaridade - se inclinarem novamente a supor que o ser é (ou pode ser) constitutivamente indeterminado em certa medida, pois supor que é determinado além do que podemos afirmar seria extrapolar o que podemos afirmar com segurança. Ora, mas afirmar que é indeterminado porque não podemos afirmar se ou como é determinado também é extrapolar o que podemos afirmar com segurança.

O próprio Heisenberg diz "princípio de inđeterminação"9 propriamente apenas no sentido epistemológico, de modo que se pode igualmente dizer - como prefiro - princípio de incerteza. Em todo caso, Heisenberg argumenta normalmente da seguinte maneira, tomando um exemplo entre muitos (o grifo é meu, para ressaltar o caráter epistemológico do princípio de Heisenberg, mesmo que ele próprio não entendesse isso claramente):

"Se quisermos saber porque uma partícula alfa foi emitida [de um átomol naquele particular
instante de tempo, teremos que conhecer a estrutura microscópica do mundo inteiro, nós,
nele, incluídos, e isso näo é factivel. Por tanto, não mais valem os argumentos kantianos
que favorecem o caráter a priori da lei da causalidade. " (p.70).

Se entendi bem, Heisenberg recusa a pertinência da distinção entre o que é e o que podemos conhecer, de tal modo que se não podemos conhecer, não importa como é ou deixa de ser, sendo melhor considerar não apenas como desconhecido e impossivel de conhecer mas como indeterminado em si, posição que por sua vez decorre de certa recusa do conceito de em si ou ao menos de coisa em si. Ou, dito de outro modo, a coisa em si, no que tem de exclusivamente em si, por definição não senđo objeto de observação empírica, então também por definição não é pertinente para o discurso científico contemporâneo.

No entanto, o que me interessou no comentário de Heisenberg é a não aplicabilidade de certos conceitos da física newtoniana - considerada pela física contemporânea como a expressão máxima e insubstituível de nosso modo de intuitivamente compreender. Por exemplo, posição e velocidade são determinações necessárias da física newtoniana, isto é, um corpo necessariamente está numa posição e a alguma velocidade. Mas o comportamento de partículas sub atômicas nem sempre é possível de descrever como o de corpos, o que só não é uma des-

9 Conforme a tradução de Jorge Leal Ferreira para a editora UnB "Fisica \& Filosotia", 1995 de Physics and philosophy: the revolution in modern science, 1958, Werner Heisenberg. 
graça completa porque eventualmente se os pode descrever de outros modos, como sendo em parte qual o comportamento de uma onda (conceito também da física newtoniana).

Heisenberg bem observa [1], e exagera [2] que

\begin{abstract}
"[1] ...a partícula elementar é, em alguma medida, despojada mesmo dos outros atributos mantidos por Demócrito: conceitos de geometria e cinemática, como forma ou movimento espaciais, a ela não podem ser atribuídos consistentemente. Se quisermos oferecer uma descrição precisa de partícula elementar - e, aí, a ênfase está no termo 'precisa' - a única coisa que poderemos apresentar é uma função de probabilidade. [2] Mas, então, percebemos que nem mesmo o atributo de 'ser' (caso este possa ser classificado de 'atributo') pertence àquilo que está sendo descrito. A funçảo de probabilidade diz respeito à possibilidade de “'ser' ou uma tendência para 'ser”" (p. 56-57).
\end{abstract}

Dizer que o ser no nível subatômico é em parte indeterminado, de modo diferente do que ocorre no mundo macroscópico - do átomo, moléculas e para maior parece-me um exagero. Ora, um elétron, por exemplo, pode ser observado como estando em determinada posição em dado momento, e depois em outra, mas não se pode disso deduzir a trajetória que percorreu entre uma observação e outra, pois simplesmente não se está falando de uma partícula que percorre trajetórias segura ou tipicamente lineares quando se fala em elétrons.

Um elétron não é uma bolinha girando ao redor de um núcleo ou percorrendo linearmente por ali qualquer trajetória, mas algo que muito grosseiramente podemos detectar mais ou menos como uma bolinha em determinado lugar no espaço, mas que também se verifica comportando-se de modos radicalmente incompatíveis com o que se poderia esperar de uma bolinha, de modo que se pode com segurança garantir que não é uma bolinha - ao contrário, sob outros aspectos o elétron se comporta de modo mais adequado a uma onda (que Heisenberg caracteriza como "substância espaihada sobre uma região de dimensões muito grandes" p. 42) do que a uma partícula (ou "substância confinada a um volume muito pequeno" - p. 42). Em outros termos, podemos dizer que um elétron, como uma onda, se espalha virtualmente pelo universo inteiro, e no universo inteiro efetuando determinações bem como de todo o universo recebendo determinações; já como uma partícula limita-se ao espaço, por exemplo, de uma bolinha, interagindo assim de modo mais marcado, por exemplo se chocando com outra partícula e comunicando a esta certo movimento ou direção.

Isso não significa que um elétron seja indeterminadamente uma partícula ou uma onda, ou que nós não saibamos ao certo se é uma partícula ou uma onda, e muito menos que seja um caso em que a não contradição ou o terceiro excluído não valem, pois é e não é uma partícula e é e não é uma onda. Significa apenas que em parte é melhor descrito como uma partícula (notadamente no momento de sua detecção) e em parte melhor descrito como uma onda (para explicar seu comportamento), na famosa complementaridade das descrições proposta por Bohr.

Mais claramente falando, uma partícula subatômica é grosseiramente verificável como uma partícula porquanto num espaço bastante limitado apresente efeitos e determinações bem marcados; mas é também compreensível como uma onda conquanto em locais muito distantes no espaço manifeste produzir efeitos, bem como também manifeste sofrer determinações de origens muito distantes no espaço, virtualmente do universo inteiro - ainda que sutis. 
Mas não me estenderei muito mais sobre estes exemplos. O texto introdutório de F. S. Northrop para a edição norte-americana, de 1962, que foi traduzido na por mim utilizada edição brasileira da UnB do livro de Bohr, nas páginas 20 e 21 trata muito diretamente do que me interessa aqui: a possibilidade e pertinência de uma causalidade ou determinação intrinsecamente limitada, ou seja, certo grau de indeterminação do ser, por oposição ao necessitarismo ou determinismo absolutos.

Conforme sintetiza Northrop, quando o objeto ou sistema de objetos que se observa é muito pequeno (e temos de ver elétrons jogando outros elétrons ou outros objetos não muito menores contra eles ${ }^{10}$ ), como no caso dos fenômenos subatômicos "a incerteza especificada pelo princípio de indeterminação de Heisenberg, para as posições e momentos lineares das partes do sistema torna-se significativa", e ao contrário, quando os objetos ou sistemas de objetos são grandes, como no caso dos objetos macroscópicos (carros, balas de canhão, foguetes de propulsão química, planetas - que observamos jogando minúsculos fótons contra eles, e não outros carros, balas de canhâo ou planetas), então "a magnitude das incertezas especificadas pelo principio de Heisenberg fica insignificante e as probabilidades associadas à posição e momento linear tornam-se despreziveis", ou seja, podemos considerar os fenômenos segundo a causalidade e determinismo fortes do senso comum e das mecânicas de Newton e mesmo Einstein.

Ora, conforme destaca Northrop, "os fenômenos subatômicos são cientificamente significativos no homem", por exemplo, nos "fenômenos neurológicos corticais [...], que são correlatos epistêmicos das idéias e propósitos humanos, diretamente introspectivos". Ou seja, nossas representações, pensamentos teóricos e práticos, e mesmo nossas paixões, em eventualmente significativa medida podem decorrer de fenômenos sujeitos a uma causalidade e determinação intrinsecamente fracas, que o contingencialismo aristotélico descreveria melhor do que o determinismo absoluto da mecânica newtoniana.

Pessoalmente não estou convencido de que os fenômenos subatômicos comportem intrinsecamente certo grau de indeterminação ontológica; apenas considero que não é total ou evidentemente absurdo supor que sim. Tampouco estou convencido de que tais fenômenos tão ínfimos tenham considerável relevância nos fenômenos físico-químicos que determinam o funcionamento de nossos corpos, especialmente nossos cérebros, e certamente devem ser muito menos relevantes do que a determinação de bem mais fortes interações através dos sentidos, da memória, da imaginação, etc., a ponto de para todos os fins a hipotética indeterminação no nível quântico ser desprezivel para a fisiologia neuropsicológica. Dado,

10 Alguns físicos ressaltam que o que precisam fazer para "ver" uma partícula subatômica é jogar violentamente contra ela uma outra partícula, o que traz grandes limitações, como se para se "ver" um carro fosse preciso jogar outros carros, ou tiros de canhão, até que um batesse no que se estava procurando, o que se deduziria ter ocorrido conquanto a explosão resultante de certo disparo fosse maior do que se só o carro jogado, ou o tiro de canhão, batesse contra um anteparo determinado. Ou seja, para vermos um carro jogamos luz contra ele e vemos a luz que esbarra nele e volta até nós, praticamente sem interferir na velocidade do carro observado; para vermos partículas tão pequenas ou menores que os quanta (pacotes de energia) de luz ou outras radiações, a observação não é mais tăo discreta, inocente ou de influência desprezivel. Ao contrário, é muito grande, como se ao iluminarmos um objeto para o ver a luz o jogasse, eventualmente em pedaços, violentamente a quilômetros de distância. 
entretanto, o modelo do efeito dominó, ou bola de neve, não é de todo absurdo supor para o ser macroscópico, especialmente no tocante ao cotidiano humano, uma eventual relevância decisiva da não absurda indeterminação ontológica do nivel quântico - ainda que isso seria decisivo apenas em si, mas por definição jamais seria objeto de experiência possivel, e por mais que o ser fosse parcialmente indeterminado, jamais perceberíamos a falta de conexão entre os eventos, da mesma maneira que não percebemos a conexão.

Minha posição é de que ambas apostas (a determinista e a indeterminista) são indecidíveis e inverificáveis, ou pior, sem importância, pois justamente é uma falsa oposição ${ }^{11}$. Alguns argumentam, ou ao menos consideram, que se o ser é totalmente determinado, não somos livres, e que, só se o ser tem certo grau de indeterminação é que podemos ser livres. Para mim, ao contrário, se o ser for indeterminado em certa medida e disso é que depende nossa liberdade, então confundimos liberdade com gratuidade ou indiferença.

Ao contrário, entendo que a liberdade só e maximamente é possivel - ou faz sentido - conforme do agente possam decorrer certas ações que dependam da vontade deste agente para serem executadas. Como diria Spinoza, a liberdade é a expressão não constrangida das determinaçöes de uma natureza, e mesmo Deus só é absolutamente livre no sentido de não ser constrangido por nada. Um homem por sua própria constituição será determinado a certas ações, e será livre se, ou até onde, não for impedido - no conflito com outros homens ou quaisquer obstáculos concorrentes.

Não estou falando de uma liberdade que cria determinações no mundo, o qual até a deliberação do agente seria indeterminado a ser de um jeito ou de outro. De fato o mundo depende da deliberação do agente para ser de determinado jeito $e$ não de outro, e o agente opera deliberações e ações que determinam 0 ser. Entretanto a deliberação livre segue ela mesma as suas determinações, e neste sentido o agente não é livre, mas apenas é de tal ou qual jeito, e por ser assim escolhe deste ou daquele modo e não de outro. Portanto não é absurdo supor que o ser seja totalmente determinado e o agente livre. Por outro lado, a contingência ontológica é desnecessária para a liberdade ética.

Cada agente racional tem suas representações de si e de suas circunstâncias, bem como o princípio de associação e comparação destas representações. Por exemplo, considera a seus valores e respectivas prioridades (suas representaçōes de si mesmo) diante de suas alternativas (suas representações de suas circunstâncias) e escolhe dentre as segundas as que parecem mais adequadas com as primeiras.

Neste sentido, a razão ou princípio de associação não é algo essencialmente mais ideal, abstrato ou formal do que real, concreto ou material, como um fenômeno físico, um efeito físico, uma propriedade física. Assim como um ácido se combinará com uma base formando um sal e água, esquematicamente uma representação de si se combinará com uma representação das circunstâncias e formará uma outra representação que se expressará num ato.

11 Como, por exemplo, diz Kant na CRPr A205-206. 
As representações que considero não são tampouco mais ideais do que reais, etc., ainda que inclusive de objetos formais. Têm sempre por substrato físico as afeç̧ões da mente considerada materialmente, relativa a um sistema nervoso concreto. Assim tais afeç̧ões têm relações causais umas com as outras e com as relações causais dos órgãos dos sentidos com os objetos exteriores. Não fosse assim, os objetos exteriores não teriam qualquer relação com as representações, e destas nenhuma conseqüência jamais adviria aos objetos exteriores, ai sim a liberdade, a ação, e já antes a percepção, seriam impossiveis.

E isso não é um realismo ingênuo, pois não se compromete em negar, por exemplo, que possamos ser cérebros acondicionados em recipientes especiais, manipulados por um cientista que ligou nossos nervos a um computador ơue nos fornece realidades meramente virtuais artificialmente geradas, como concebeu $\mathrm{H}$. Putnan. Afinal, já que não tem solução, qual o problema?

Se alguém escolhe peixe em lugar de frango, isso foi uma ação livre se a escolha foi motivada pelas disposições biológicas, culturais e circunstanciais do agente. Por exemplo, poderia estar enjoando de comer frango após repetidas refeições e, em dada ocasião, escolheu peixe; ou poderia ter lido que a taxa de contaminação da carne de frango chegara a graus alarmantes ao passo que conhecia melhor e confiava mais na procedência do peixe do restaurante em que fazia sua refeição, e por isso escolheu peixe; ou por identificação ou sectarismo politico poderia querer negar um dos símbolos do sucesso material do plano Real e do governo Fernando Henrique, e por isso escolheu peixe em detrimento do frango; poderia escolher o peixe por identificação e voluntária submissão religiosa, digamos, se cristão e na semana santa; poderia mesmo pedir uma sugestão ou ter escolhido de modo relativamente aleatório, mas livremente porquanto quis comer algo e decidiu optar por uma sugestão ou um método aleatório para definir o quê.

Assim a liberdade humana depende da identificação do agente com sua ação. Por exemplo, não dizemos que alguém caiu moralmente livre de uma altura de dois mil metros, após ser empurrado de um avião, embora o fenômeno físico em questão se chame "queda livre" - isto é, não relativamente impedida, ao contrário de num pêndulo ou plano inclinado. O homem jogado de um avião, ou que acidentalmente cai de um avião não se identifica com esse evento de queda; ao contrário, o evitaria se pudesse e soubesse como.

A vontade humana é um fenômeno neuropsicológico e social muito complexo, mas a noção de probabilidade pertinente não é a do acaso indeterminista, mas é a da imprecisão decorrente da complexidade do fenômeno, como nos fenômenos meteorológicos, que podem ser descritos numa base determinista forte. E como a física quântica (que para ver seus objetos tem que jogar contra as partículas subatômicas outras partículas subatômicas não muito menores, com conseqüências bem diferentes da de observar bactérias, carros ou planetas jogando contra eles, bem menores do que eles, partículas subatômicas como elétrons ou fótons), na pedagogia, psicologia, psicanálise e demais investigações e intervenções de abordagem clínica tem-se que "jogar" uma pessoa "contra" outra pessoa, de modo inevitavelmente interativo ou mesmo invasivo e perturbador, de tal modo que mesmo quando a pessoa observada não sabe que está sendo observada, a pessoa que observa é problematicamente perturbada pelo seu objeto. 
Aristóteles - e os vários que insistem muito na indeterminação do ser - parece ter pensado que a liberdade deveria ser ontologicamente mostrada como possível, ou seja, que o ser é tal que a liberdade é possivel. Eu, ao contrário, penso que nossa liberdade é provada por um argumento pragmático-transcendental, assim como nossa razão: como ao dizermos qualquer coisa temos de nos pressupor como capazes de sermos racionais, também ao agirmos temos de nos pressupor como capazes de agir livremente, e isso não pode depender da determinação ou indeterminação do ser.

Aliás é impossivel conceber que o ser não seja ao menos em parte determinado, pois neste caso a razão seria impossivel, e esta é uma conclusão impossivel. Portanto é necessário considerar que se o ser é, é determinado; e é necessário considerar que o ser é. $\mathrm{O}$ ser do futuro também necessariamente tem que ser ao menos em parte determinado, ou o futuro não teria absolutamente qualquer ser. Como o futuro não pode ser pensado como totalmente indeterminado em relação ao passado e ao presente, ou simplesmente não seria futuro mas mais ser a surgir por si mesmo, o futuro é ao menos em parte determinado, a saber, naquilo que agora já estão dadas as causas suficientes - isto é: determinantes. O futuro, portanto, ao menos em parte, é o desdobramento necessário do ser presente.

Por exemplo, se eu digo agora que irei ao cinema amanhã ver determinado filme, é razoável pensar que já agora esteja determinado que de fato ou vou ao cinema amanhã, ou que, de fato, eu vou acabar não indo ao cinema amanhã. A aparente indeterminação associada a possibilidade de, de fato, eu ir ou não ao cinema amanhã, decorre de minha ignorância de outros eventos que podem já agora estar em inexorável curso sem que eu saiba, por exemplo, um parente pode estar se encaminhando para um enfarte amanhã as $7 \mathrm{~h}$ da manhã, que o levará inevitavelmente à morte, pois não haverá ninguém para o socorrer a tempo, mas apenas alguém para a tempo o descobrir já morto e isso comunicar a mim e outros parentes, de tal modo que acabarei, dadas minhas relações de fato com meus parentes, por ir ao velório e não ao cinema.

A aparência de casualidade ou indeterminação do meu futuro amanhã ser ir ao cinema, a um velório ou outra alternativa não prevista depende de minha ignorância das circunstâncias. Se eu fosse muito obsessivo eu poderia dizer "se nenhum parente morrer nem me aparecer um programa melhor, amanhã eu vou ao cinema..." e mesmo assim poderia confessar certa ignorância do tipo "mas se morrer um parente pouco íntimo e me aparecer um programa muito melhor, aí já não sei o que vou preferir"... o que não quer dizer que eu já não seja tal, hoje, que inevitavelmente escolherei um e preterirei outro.

Inclusive minha razão não é mais que certa característica entre outras que eu tenho, e as caracteristicas do ambiente que me envolve interagirão com minhas características internas produzindo uma resultante, determinada possivelmente desde sempre, que determinará que, por exemplo, livre e necessariamente vou ao cinema amanhã.

Essa determinação e causalidade fortes me tornam menos livre em algum sentido relevante? Não. No que o acaso ou indeterminação no meu cérebro, nos meus humores, desejos e fantasias me tornariam mais livre do que se tais eventos 
ocorrerem de modo rigidamente causal? Em nada. No que o acaso quanto aos eventos com os quais eu serei confrontado me tornam mais livre do que se o mundo em que vivo for rigidamente causal e o tempo como passado, presente e futuro apenas uma ilusão constitutiva de meu modo finito de conhecer? Igualmente em nada.

Por certo este projeto já seria melhor concluído se em lugar de Aristóteles e da interpretação da escola de Copenhague da fisica quântica eu tivesse por exemplo percorrido Spinoza e o mecanicismo moderno da física clássica, só eventual e adicionalmente fazendo algumas referências aos antecedentes e alguns contrastes com posições contrárias. Apresento esta comunicação, em todo caso, como o registro de um percurso que me apontou uma seqüência que pretendo seguir. 